\title{
Investigating Prospective Teachers' TPACK and their Use of Mathematical Action Technologies as they Create Screencast Video Lessons on iPads
}

\author{
Fernanda Cesar Bonafini ${ }^{1}$ (D) $\cdot$ Younhee Lee ${ }^{2}$ \\ Accepted: 17 December 2020 / Published online: 16 January 2021 \\ (C) Association for Educational Communications \& Technology 2021
}

\begin{abstract}
The increasing number of technological devices available in schools, aligned with curriculum guidance, set an expectation for mathematics teachers to incorporate these devices into their teaching. This qualitative study investigated prospective teachers' use of TPACK and mathematical action technologies as they created screencast video lessons using iPads. Results showed prospective teachers' effective use of pedagogical techniques and the screencast app as an amplifier tool, according to the amplifier-reorganizer metaphor. Half of the participants used mathematics technology to confirm and expand the results they had found without technology. The other half had mathematics technology integrated into their solution exercising the balance among TPACK components. For some, their use of the mathematical tool had the potential of expanding the mathematical repertoire of virtual students. We conclude by making recommendations for teacher educators to implement cycles of learning for pre-service teachers to design, enact, and reflect upon the creation of screencast video lessons.
\end{abstract}

Keywords Screencast video lessons $\cdot$ TPACK $\cdot$ iPad $\cdot$ Amplifier $\cdot$ Reorganizer $\cdot$ Pre-service teachers

\section{Introduction}

The increasing number of technological devices available in schools (Cambridge Assessment International Education 2018), aligned with curriculum guidance such as Principles and Standards for School Mathematics (National Council of Teachers of Mathematics 2000) set an expectation for mathematics teachers to meaningfully incorporate these available devices into their teaching. Lately, due to the outbreak of the COVID-19 pandemic, the demand for mathematics teachers who effectively promote learning with technologies has been even higher. To make technology integration more effective, mathematics teachers should transition from their traditional

Fernanda Cesar Bonafini

fcb5100@psu.edu

Younhee Lee

leey6@southernct.edu

1 Mathematics Department, The Pennsylvania State University, 005 McAllister Building, University Park, PA 16802, USA

2 Mathematics Department, Southern Connecticut State University, Engleman Hall D135, New Haven, CT 06515, USA teaching practices to a teaching in which technology plays an essential role in students learning (Mishra and Koehler 2006). For that, these teachers need experiences that allow them to fully integrate technology in their teaching practices.

The pressure for integrating technology into teaching also makes latent the demand for pre-service mathematics teachers to use technology in their classrooms. Thus, teacher educators need to create opportunities for pre-service mathematics teachers to be "knowledgeable about both the technology itself and its implementation to meet educational goals" (DeCoito and Richardson 2018, p. 362). Teacher preparation programs have created opportunities for pre-service mathematics teachers to interact with conveyance technology (non-mathematical tools) and mathematical action technology. Conveyance technologies are defined by Dick and Hollebrands (2011, p. xi) as those "used to convey, that is, to transmit and/or receive information" such as presentation technology (e.g., PowerPoint, Whiteboards, Learning Management Systems). Mathematical action technologies are those that "can perform mathematical tasks and/or respond to the user's actions in mathematically defined ways" (p. vii) such as dynamic geometry software (e.g., GeoGebra) or computer algebra systems (e.g., TI-Nspire), among others. Usually, pre-service teachers interact with these technologies 
separately while in college, for example, by using a whiteboard (conveyance technology) to teach a mathematical concept or using GeoGebra to make geometrical constructions as they learn geometry content.

Among the diverse types of technological tools that can be useful in secondary school mathematics, mobile devices such as tablets emerge as a promising tool to be used by teachers and students in the classroom. The possibility of using the same device in different classes makes tablets even more appealing in complementing teachers' pedagogical approaches (Cochrane et al. 2013; Goodwin 2012; Haßler et al. 2016). Affording teachers opportunities for using tablets may provide them a chance to experience conveyance and mathematical action technologies in an integrated way.

\section{Literature Review}

\section{Teachers' Use of Tablets}

We identified two main strands in the literature of teachers' use of tablets in classrooms. In the first strand, teachers use tablets in their classrooms with the purpose to convey information, to give students access to a variety of resources, and to foster communication and collaboration with students. In the second strand, teachers use tablets with content specific apps with the purpose to promote students' interaction with the content being taught. In our case, mathematics content.

In the first strand, research reports teachers implementing tablets in their classes for students to engage with educational and non-educational games (Geer et al. 2017; Ciampa 2014), electronic textbook (Quillen 2011), and video or tutorial watching (Walsh and Farren 2018; Ciampa 2014). Literature in this strand also describes teachers using tablets for: (i) personalization of instruction based on students' learning preferences (Geer et al. 2017; Ciampa 2014), (ii) resources sharing (Jahnke and Kumar 2014; Geer et al. 2017), (iii) communication tool between teachers and students (Walsh and Farren 2018; Ciampa 2014; Heinrich 2012), (iv) collaboration among students (Jahnke and Kumar 2014), and (v) students' assessments (Quillen 2011).

In the second strand, research report teachers implementing tablets with content specific apps. In the case of mathematics teaching, teachers' use of mathematical apps aims to assist and support students in their process of learning. Some of these studies show teachers using math apps to develop students' symbolic understanding (Outhwaite et al. 2017; Pitchford 2015). Other studies show teachers implementing number sense and numeration apps (e.g., Motion Math Zoom) to help students consolidate their knowledge on decimals and place value (Zhang et al. 2015).

The literature on teachers' use of math apps also shows teachers implementing math game apps to raise students' arithmetic fluency (van der Ven et al. 2017; Schacter and Jo 2017). These studies have shown pupils improving their arithmetic efficiency when solving game tasks. Teachers have also implemented tablets by using virtual manipulatives to teach students about geometrical shapes recognition (GecuParmaksiz and Delialioglu 2019), and geometry apps to foster students' creation and manipulation of geometrical representations and symmetries (Korenova 2017). Other studies have also shown teachers using drill and practice content apps (i.e., iTooch) to reinforce mathematical concepts and prepare students for standardized tests (Mouza and Barrett-Greenly 2015).

A third strand about teachers' use of tablets in classrooms started to emerge in the literature around 2013, and it is related to teachers implementing tablets with Show and Tell apps. This new category of apps has the potential of embedding the goals of the two previous strands. Show and Tell apps such as Explain Everything, Show-me, and Educreations are applications that transform tablets into portable whiteboards, in which teacher and/or students can use voice, handwriting, and embedded content apps in tandem, with the option of realtime voice and screen recording (Ingram et al. 2018; Williamson-Leadley and Ingram 2013).

By using a tablet with a screencast app, teachers can teach the mathematical content with the option of incorporating mathematical app/tools in their teaching. The content of the lesson can be recorded inside the app, adding the audio of that lesson. This video lesson can be later shared by the teacher with his/her colleagues and can be shared with students who may watch the video lesson on other devices such as computers, smartphones, or tablets. Tablets with a screencast app also can be used by students to record their thinking-aloud processes when they are solving mathematical problems (Ingram et al. 2018).

Ingram, Williamson-Leadley, and colleagues (Ingram et al. 2018; Ingram et al. 2015; Ingram et al. 2016; WilliamsonLeadley and Ingram 2013) have investigated different ways Show and Tell apps could be used by students during their problem-solving in the classroom. In their studies, they noticed as students used the screencast app in their problem solving, they were encouraged to speak about their thinking process (thinking aloud), which helped the teacher to access students' thinking as well as student's difficulties with the content. According to the authors, teachers who introduced screencast apps as a tool for their students to solve problems reported a higher level of mathematical engagement in their classroom when compared to students solving problems without the tool (Ingram et al. 2018).

Although Ingram, Williamson-Leadley, and colleagues have been pioneers in researching the use of Show and Tell apps in the classroom, their studies have been focused on students engaging with the app, instead of teachers using a tablet for creating screencast video lessons with Show and Tell apps. For us, the creation of screencast video lessons with 
mobile devices can be considered an opportunity for preservice teachers to experience the synergy between the two strands presented in the literature. The process of creating and delivering a screencast video would also offer unique opportunities for pre-service teachers to acquire experiential learning in integrating their technological, pedagogical, and content knowledge.

\section{Mathematics Teachers' Technological Pedagogical and Content Knowledge (TPACK)}

Building on Shulman's $(1986,1987)$ notion of pedagogical content knowledge and the eminent need for helping teachers to utilize technology in their classroom effectively (National Council of Teachers of Mathematics 2000), individuals and organizations in the field (American Association of Colleges for Teacher Education (AACTE) Committee on Innovation and Technology 2008; Koehler and Mishra 2005; Niess et al. 2009) have identified and developed a new way of conceptualizing the types of knowledge needed by teachers - namely, Technological Pedagogical and Content Knowledge [TPACK] Fig. 1. The TPACK framework has three main domains: technological knowledge, pedagogical knowledge, and content knowledge. Technological Knowledge (TK) comprises the broad use of technology including both conveyance and mathematical technologies. Pedagogical Knowledge (PK) comprises teachers' practices and strategies. Content Knowledge (CK) comprises the subject matter that is learned or taught.

The intersections of these three main domains consist of: (a) Pedagogical Content Knowledge (PCK), representing the "pedagogy that is applicable to the teaching of specific content" (Koehler and Mishra 2005, pp. 133-134), (b) Technological Content Knowledge (TCK), representing "teachers' knowledge of how a subject matter is transformed by the application of technology" (Koehler and Mishra 2005, p. 134), (c) Technological Pedagogical Knowledge (TPK), representing "knowledge of how technology can support pedagogical goals" (Koehler and Mishra 2005, p. 134). Lastly, the intersection of TK, PK, and CK represents Technological Pedagogical Content Knowledge (TPACK), meaning "the knowledge required by teachers for integrating technology into their teaching in any content area" (Schmidt et al. 2009, p. 125).

As a way of better understanding and promoting teachers' TPACK, researchers and scholars in the field have developed guidelines (AMTE Committee on Innovation and Technology 2009), instruments for assessing teachers' TPACK (Schmidt et al. 2009), and a model for describing the development of teachers' TPACK (Niess et al. 2009). Others have used the TPACK framework as a tool for understanding teachers' experiences and perceptions as they teach with technology. For example, Landry (2010) built on the TPACK to design
Fig. 1 TPACK framework. Reproduced by permission of the publisher (2012 by tpack.org)

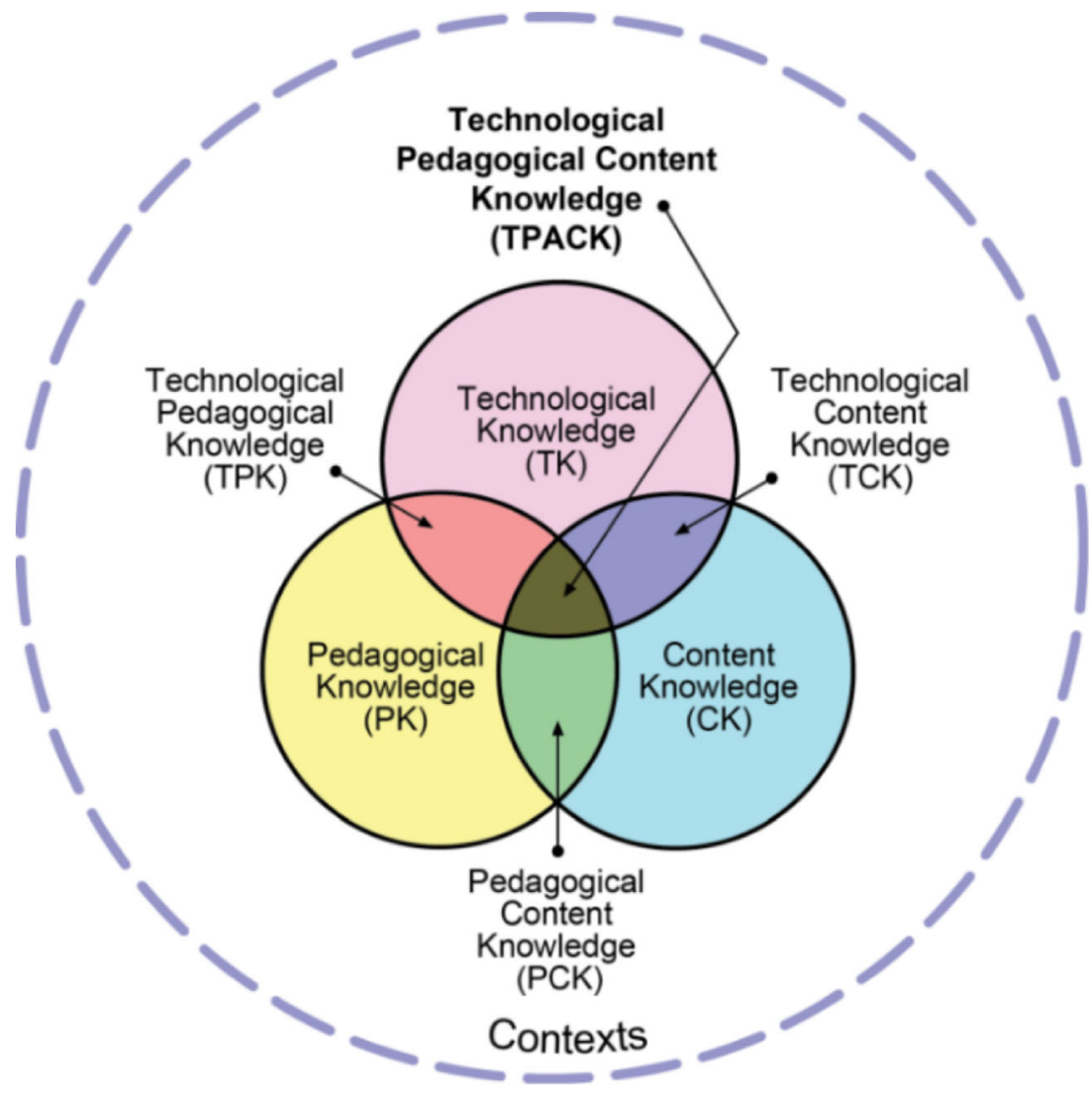


and validate a survey instrument that captures middle school mathematics teachers' knowledge, beliefs, and needs concerning technology. Lee and Hollebrands (2008) reported pre-service teachers' learning with data analysis tools in their teacher preparation program and recommended teacher educators to provide experiences to engage pre-service teachers in doing mathematics themselves using technology for TPACK development. Our study also aims to describe pre-service teachers' experience with technology with a lens of TPACK, but in the unique and under-researched format of combining a screencast app and mathematical technology. More discussions as to how the TPACK framework is used in this study will be presented in the Conceptual Framework and Methods sections.

In this paper, we aim to contribute to the screencast videos literature in K-12 education by using Show and Tell apps and the availability of tablets in schools to design opportunities for pre-service teachers to experience the creation and implementation of digital videos. The process of creating a digital video will provide opportunities for pre-service teachers to learn how to teach mathematics with technology as well as learning to balance the TPACK's components. Thus, this study investigates the following research questions:

1. What technological, pedagogical, and mathematical knowledge is presented in screencast video lessons created by pre-service teachers?

2. How do pre-service teachers use mathematical action technologies in their screencast video lessons?

In the next section, we present the conceptual framework, followed by methods used in this investigation. After that, the results, discussion, and conclusion are presented.

\section{Conceptual Framework}

Knowing that the creation of screencast video lessons allows pre-service teachers to practice the integration of their pedagogical, technological, and mathematical knowledge, this study makes use of the TPACK framework. In this study, we have used definitions from Koehler and Mishra (2005), and survey items developed in Schmidt et al. (2009) to identify indicators of the seven domains of TPACK. However, as pre-service teachers who are learning how to teach mathematics and how to integrate technology at the same time, they might encounter particular challenges as to their use of technology. For example, Koehler et al. (2017) focused on the technology component and looked into levels of TCK, TPK, and TPACK in 589 online portfolios created by (not necessary mathematics nor pre-service) educators in their program. They have found "rich artifacts" were included in the portfolios at a low rate, which suggests participants' "limited knowledge of the interconnections of TPACK" (p. 54). These recent results reinforce the need to investigate teachers' rich implementation of technology in their practice.

In other words, while the TPACK framework helps understand different domains of teacher's knowledge utilized in a mathematical lesson using technology, an in-depth analysis of such a lesson would merit an additional lens on how the technology is used to enhance students' understanding of mathematics. Pea's (1985, 1987) amplifier/reorganizer metaphor makes possible the analysis of "how" and has the potential to characterize teachers' TPACK development in terms of the advancement in levels of using a technological tool. We first explain the constructs of amplifier and reorganizer as described by Pea $(1985,1987)$ and then introduce levels of implementation of mathematical action tools (see Fig. 2) as a lens for characterizing the use pre-service teachers made of mathematical tools in their screencast videos.

Pea (1985) proposed the amplifier and reorganizer metaphors to describe how cognitive technologies can be used in education. According to the author, a piece of technology is implemented as amplifier when the technological tool is used to perform the same tasks that could be done by hand (without technology). When using technology as amplifier, pre-service teachers will have a gain in efficiency as they create and present mathematical computations and/or graphical representations with higher accuracy than doing by hand. However, using technology as an amplifier will not push students to expand or modify their mathematical thinking as they engage with the video.

For the author, technology is implemented as reorganizer when the technological tool is used in a way that promotes a change in one thinking about the mathematics embedded in the problem. When using technology as reorganizer, preservice teachers will have the chance to expose and to connect concepts that would be difficult to explore without the technological tool. In this study, cognitive tools are mathematical action technologies, as defined Dick and Hollebrands (2011).

When dealing with pre-service teachers creating video lessons, the screencast tool is assumed to be a conveyance technology tool, and the mathematical action technology is considered to be a cognitive tool. Since the implementation of mathematical action technologies happens embedded in levels inside the screencast tool, we represented these levels as an inverted pyramid, as shown in Fig. 2.

In level zero, pre-service teachers use the screencast tool for writing and drawing as they record the video lesson (see Fig. 3a). In this level, there is no use of mathematical action technologies. Level one implies that pre-service teachers go beyond level zero by using a mathematical action tool in the form of screenshots to enhance and/or augment their lesson (see Fig. 3b). In this level, the mathematical action technologies are used as amplifiers since pre-service teachers' goals are of expediting and enhancing the mathematical representations implemented in the video lesson. Level two occurs when pre- 
Fig. 2 Levels of implementation of mathematical action tools

\section{Levels of Implementation of Mathematical Action Tools}

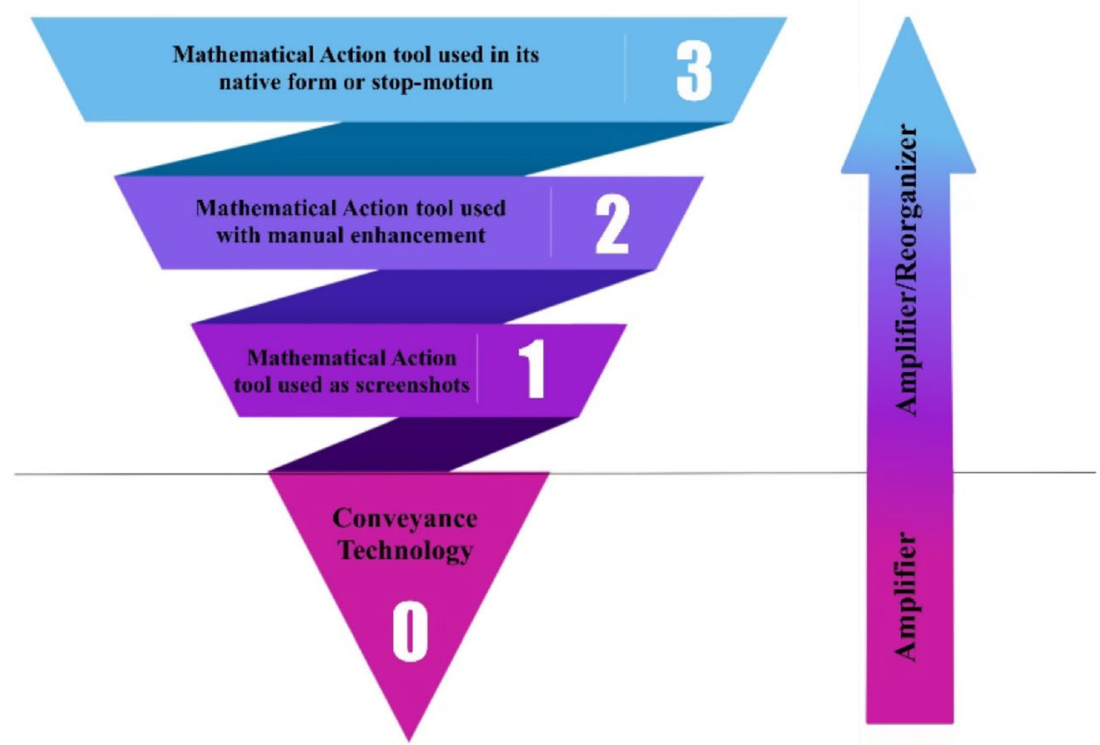

The general form of a quadratic function is $f(x)=a x^{2}+b x+c$ where $a, b$, and $c$ are real numbers and $a \neq 0$.
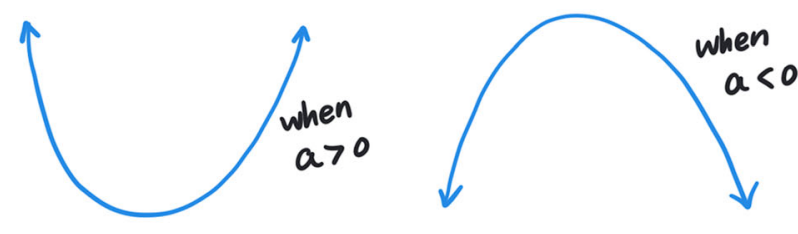

(a)

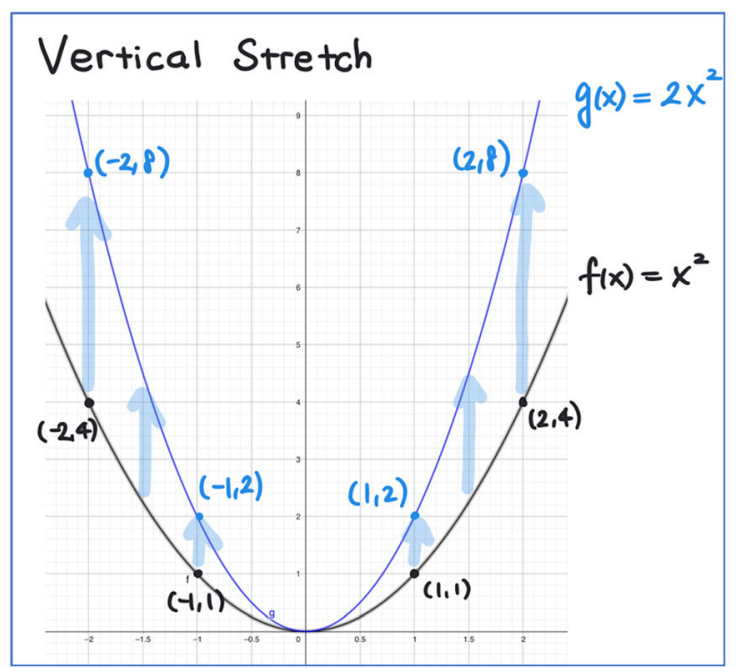

(c)
Given the vertex $(2,-3)$ and $y$-intercept at $(0,1)$ we can find the vertex form of the quadratic function on the graph:

$$
\begin{gathered}
f(x)=a(x-2)^{2}-3 \\
f(0)=a \cdot(-2)^{2}-3=1 \\
\therefore a=1 \\
f(x)=(x-2)^{2}-3
\end{gathered}
$$

(b)

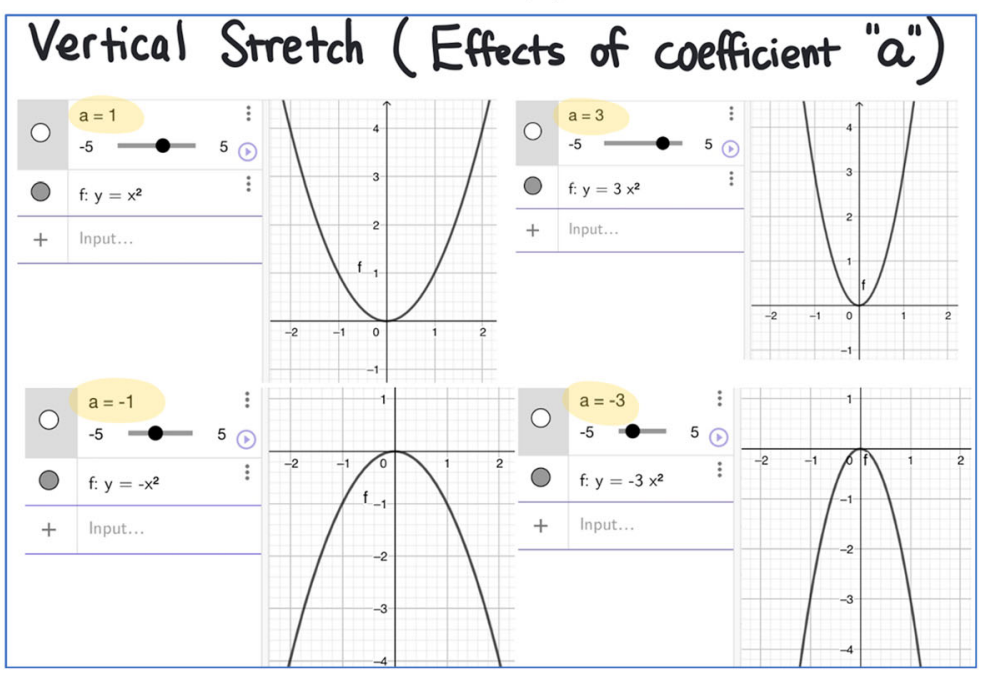

(d)

Fig. 3 Examples of the four levels of implementation of mathematical action tools 
service teachers go beyond level one by doing some manual enhancement on the screenshots of the mathematical action technologies-for example, using the pointer movement to emulate (imitate) the dynamic native feature of the mathematical action tool (see Fig. 3c).

Level three happens when pre-service teachers go beyond level two by using the mathematical action tool in its native form, including real-time manipulation or stop-motion video in which multiple screenshots bring static objects to life (see Fig. 3d). In levels two and three, the mathematical action technologies start to have the potential to be used as reorganizer. In these levels, pre-service teachers' goals are of exploring connections between different parts of mathematics and/or making salient some aspects of a mathematical concept, which would be difficult to carry out without the use of these mathematical action technologies.

\section{Methods}

Qualitative analysis (Zhang and Wildemuth 2009) was conducted by collecting participants' videos and other submitted materials and characterizing instances of technological, pedagogical, and content knowledge exhibited by participants and their use of mathematical action tools.

\section{Context and Participants}

Participants in the study were pre-service secondary mathematics teachers from two different American universities registered in courses that provided them the experience of teaching mathematics with technology. Sixteen students participated in this study. Researchers used purposeful sampling to identify and select information-rich cases, as described by Cresswell and Plano Clark (2011), and Patton (2002). The current paper presents the analysis of four participants: Melissa, Jane, Olivia, and Richard (pseudonyms). All students were toward the end of their secondary mathematics education program, and it was expected that they would rely on their existing mathematical and pedagogical knowledge developed in previous content courses and methods courses.

The project of creating a video lesson was introduced as one of the major projects in the course and intended to provide an opportunity for participants to implement their pedagogical, mathematical, and technological knowledge in an integrated way towards developing their TPACK. The project was divided into three sub-sections: (1) choosing a mathematical problem as shown in Table 1 and planning a video lesson on how to solve the problem for secondary students, (2) creating a 10-min video lesson using a mathematical app called Explain Everything, and (3) watching each other's videos in class and reflecting on their own videos.

\section{Data Sources}

Data sources include: (a) participants' lesson plans containing their own solution to the problem, (b) their screencast video lesson files, and (c) their reflection upon their own video creation. To build answers to the research questions, researchers used participants' screencast video lesson files as primary data sources, and participants' lesson plans and their individual reflections as secondary data sources.

\section{Data Analysis}

Researchers analyzed participants' video lessons in tandem with their respective lesson plans coding for TPACK components and instances in which participants' video lessons presented different levels of implementation of mathematical action tools (i.e., amplifier and/or reorganizer). Table 2 displays a sample of the theory-driven codes (DeCuir-Gunby et al. 2011), along with the definitions, examples, and data sources used by researchers. See supplementary material for a full view of Table 2.

Researchers used F5 Transcription software to code participants' screencast videos excerpts of data that contained insights regarding the TPACK components. The same procedure was used by researchers to identify different levels of implementation of mathematical action tools. Using the TPACK framework, researchers also cross-checked each coded passage of data retrieved from their screencast videos with participants' lesson plans. Participants' levels of implementation of mathematical action tools in their screencast videos were compared to their personal reflections looking for clarification about participants' choice and usage of that mathematical tool.

Researchers coded the documents as a group using the TPACK framework after initially coded the same documents individually.
Table 1 Problems chosen by participants

\begin{tabular}{ll}
\hline Participant & Problem chosen by participants \\
\hline Melissa & Find the minimum value of $x^{2}+y^{2}$ for all points $(x, y)$ on line $2 x+y=1$. \\
Jane & If $a$ and $b$ are numbers such that $(a-4)(b+6)=0$, then what is the smallest possible value of $a^{2}+$ \\
& $b^{2} ?$ \\
Richard and & Two mutually perpendicular lines pass the center of a unit square and divide the square into \\
Olivia & four regions. Prove that the four regions have equal areas. \\
\hline
\end{tabular}


Table 2 Sample of theory-driven codes

Code Description

Content Knowledge (CK)

Definition: CK refers to "knowledge about actual subject matter that is to be learned or taught." (Mishra \& Koehler, 2006, p. 1026).

Indicators of CK include actions such as: solving mathematical problems correctly, proving mathematical statements deductively, communicating mathematical ideas effectively, and using mathematical representations properly.

Excerpt from the data that exemplifies CK:

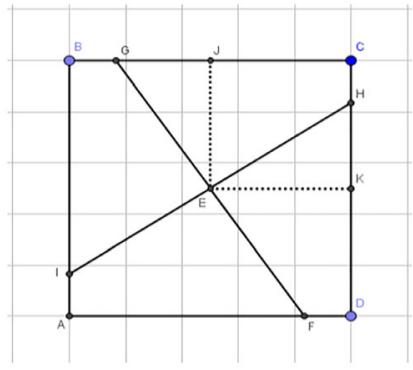

Solution: I want to show that the area of each region in the unit square is one fourth of the total area of the square. Let the intersection point through the center of the unit square be called E. From the statement, line GF and line HI are perpendicular to each other. Let $\mathbf{J}$ be the midpoint of line $\mathrm{BC}$ and $\mathrm{K}$ be the midpoint of line $\mathrm{CD}$. The line segment $\mathrm{EJ}$ is perpendicular to the line segment EK. I want to prove that the area of the quadrilateral EHCG is equal to the area of the square EKCJ. Well,

And,

$$
\angle \mathrm{JEG}+\angle \mathrm{HEJ}=\angle \mathrm{HEG}=90^{\circ}
$$

$$
\angle \mathrm{KEH}+\angle \mathrm{HEJ}=\angle \mathrm{KEJ}=90^{\circ}
$$

Therefore, $\angle \mathrm{JEG} \cong \angle \mathrm{KEH}$. We also know that the line segment $\mathrm{EJ} \cong$ line segment $\mathrm{EK}$, so by properties of congruent triangles, we can conclude that $\triangle J E G \cong \triangle K E H$.

Because these triangles are congruent and their areas both share the area of the quadrilateral EHCJ, we know that the areas of these four regions are equal.

(Olivia, Lesson Plan).

Pedagogical Content Knowledge (PCK) Definition: PCK means representing the "pedagogy that is applicable to the teaching of specific content" (Koehler \& Mishra, 2005, pp. 133-134).

Indicators of PCK include actions such as: explanations about solving the problem using mathematical

pre-requisite knowledge, attention to address of common misconceptions, explanations of different approaches to solving a problem, and use of multiple representations.

Excerpt from the data that exemplifies PCK:

"Recall that when we are given a typical quadratic equation, we use factoring in order to find the "zeros" or the x-intercepts of the function" (Jane, Lesson Plan).

Technological Pedagogical Content Knowledge (TPACK)

Definition: TPACK means "knowledge required by teachers for integrating technology into their teaching in any content area" (Schmidt et al., 2009, p. 125).

Indicators of TPACK include actions such as: combining mathematics, technology, and teaching, and using strategies that integrate content, technologies, and teaching approaches.

Excerpt from the data that exemplifies TPACK:

"Now, I will show you how to do it geometrically. For the geometric representation, I will use Geogebra to display the model I made for this problem. There are multiple uses for GeoGebra. GeoGebra is useful in a classroom because of the many tools and skills that you can use with it. For example, I will be showing you how to get a solution for this problem using basic tools in GeoGebra. First, we are going to show the axes and grid lines so we can get an exact solution. I will then use the input bar to graph the equation $y=$ $1-2 x$. Thus, you can see the line that was graphed onto GeoGebra. I will then create a slider to set as the radius for a circle which we place the center at the origin. We do this because we can think of the expression $x^{2}+y^{2}$ as an equation for a circle if we set the expression equal to $r^{2}$. I will name the slider $r$. I will then create a circle with radius $r$ and center at the origin. I will then drag the slider until the line that we graphed earlier is tangent to the circle. This radius is the minimum value for the expression, which is . 45 . This is the same value we got for the algebraic way" (Melissa, Lesson Plan). 
inconsistency in the coding, the applied code was the one based on the majority of the evidence given in the data excerpt.

During the data analysis, researchers used the triangulation process to validate data, as described by Golafshani (2003) and Moon (2019). At the last stage of analysis, researchers together created research memos for each student. These memos were used by researchers as a tool to extract meaning from the data (Lapan et al. 2012). The research memos were later compiled to form a statement about how participants exhibited TPACK components in their screencast videos, and how they used mathematical action technologies in their screencast videos.

\section{Results}

In this section, we present the results of the analyses conducted to examine how pre-service teachers presented technological, pedagogical, and mathematical knowledge as they made screencast video lessons using an iPad. It also explores how pre-service teachers used mathematical action technologies in their screencast video lessons.

Research Question 1: What technological, pedagogical, and mathematical knowledge is presented in screencast video lessons created by pre-service teachers?

All participants acknowledged the presence of virtual students while solving the mathematical problem in their screencast video lessons. Participants used well their screen space to distribute the information in a visible and organized manner, as shown in Fig. 4. Participants coordinated their voice with the information that was presented on the screen, although none of them asked for virtual students to pause the video to think about the problem or its solution process. Melissa and Olivia maintained a steady pace throughout the video, displaying appropriate pedagogical knowledge.

All participants posed questions to their virtual students throughout their screencast video lessons, except Melissa. Melissa and Richard recalled pre-requisite concepts at the beginning of their videos, while Olivia and Jane recalled concepts as they were needed through the problem-solving. Different from Melissa's approach, Richard, Olivia, and Jane used color coding in their multiple representations in order to facilitate students' identification of the object being discussed and help further their understanding of the mathematical procedures shown in the video.

Among the four participants, Olivia parsed well the information in her video so that virtual students would be able to follow along with the multiple steps and the multiple graphical representations implemented by her in the solution of the problem as seen in Fig. 5. Melissa used a "tour guide mode" while explaining the problem. She first informed students what she was going to do so that they would be able to understand the results on the screen, as she stated:

I will be showing you how to get a solution for this problem using basic tools in GeoGebra. First, we are going to show the axes and grid lines so we can get an exact solution. I will then use the input bar to graph the equation $y=1-2 x$.

Different from the other participants, the pedagogy implemented by Jane and Richard in their videos gave us a feeling that they were teaching their classmates instead of secondary students. Jane quickly explained essential details from her
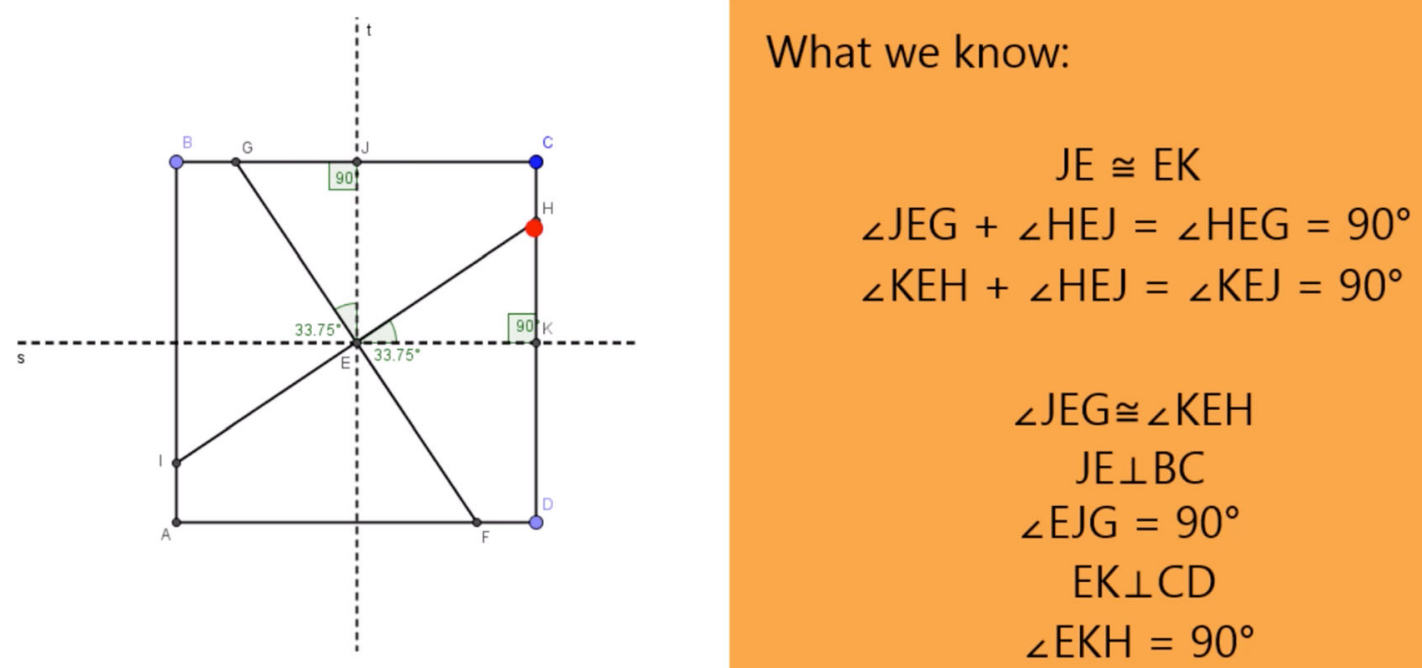

Fig. 4 Olivia's use of the screen space 


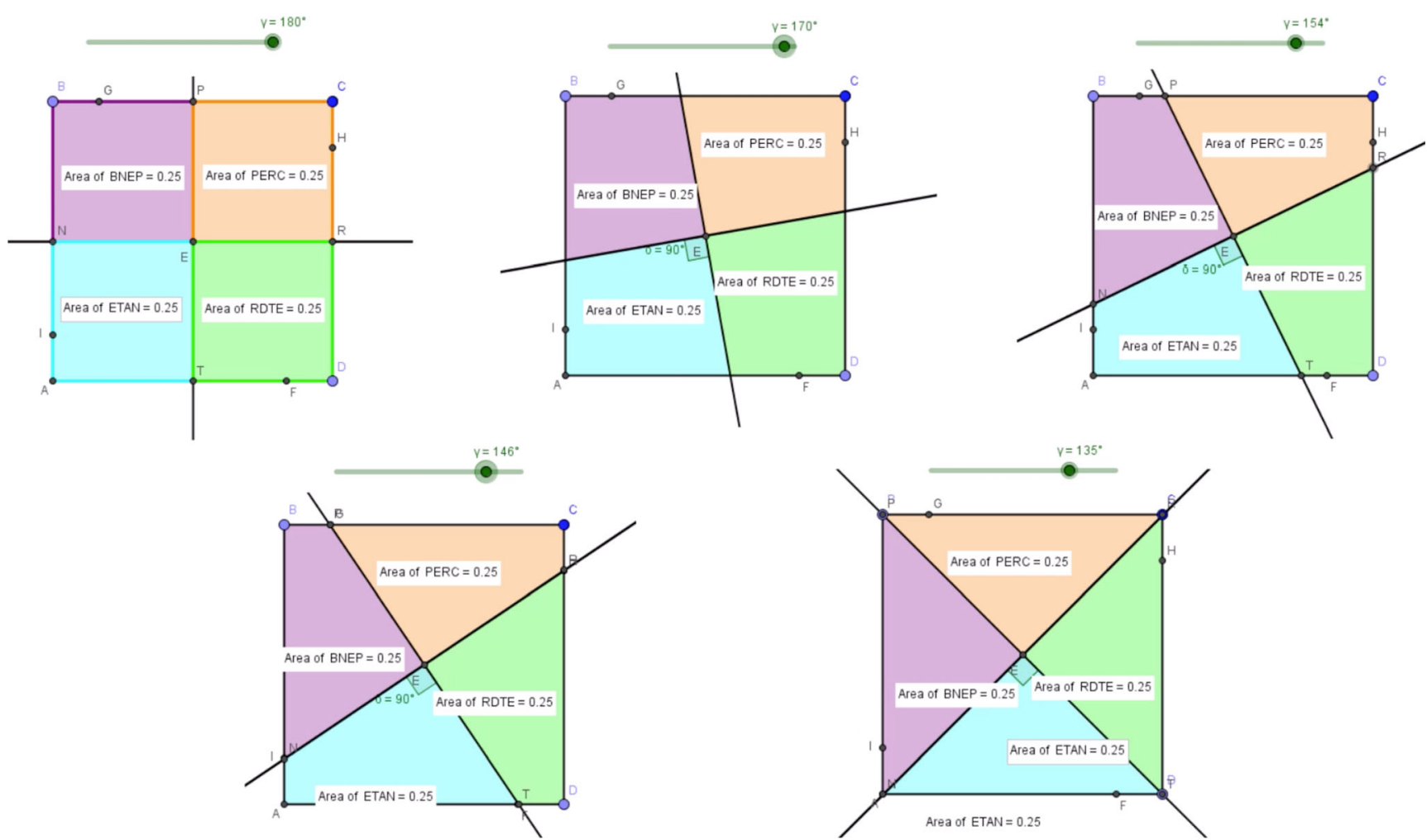

Fig. 5 Olivia's use of multiple representations to show the sameness of four areas

mathematical representations, and Richard produced a technical demo video for the use of GeoGebra software.

In terms of mathematical knowledge, all participants correctly solved their problems in their videos, and all participants used GeoGebra for their mathematical representations. Jane and Richard decided to draw some mathematical representations by hand first, and then, implement mathematical representations from GeoGebra. By doing so, Jane and Richard introduced imprecisions in their representations, with Richard drawing an inaccurate image for a square (see Fig. 6).

By drawing this inaccurate representation by hand, Richard may have given students the idea that a square could have adjacent sides with different lengths. Besides this incorrect

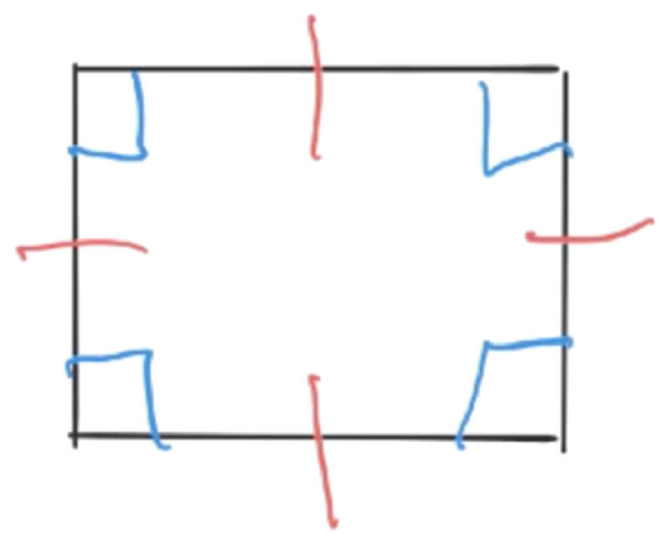

Fig. 6 Richard's inaccurate representation of a square representation, Richard also lacked attention to the mathematics details such as marks to identify different sides in a geometric figure, and missing labels for perpendicular lines.

Olivia was the only one who used pre-created slides in the video lesson, which facilitated the flow of her explanation process as shown in Fig. 7. The use of pre-created slides also supported her in making a cohesive use and an excellent coordination of multiple representations previously created in GeoGebra. Although Olivia had solved her problem numerous times before her video recording, she presented the mathematical proof as a connection across mathematical ideas and concepts.

Richard's and Olivia's use of mathematics technology was integrated into their solution. In contrast, Melissa's and Jane's use of mathematics technology was in the service of confirming and expanding the results they found algebraically at the beginning of their video. All participants demonstrated a solid knowledge of their chosen mathematical tool (i.e., GeoGebra).

Melissa and Richard implemented GeoGebra in real-time in their videos. Despite this similarity, their videos progressed in distinct ways. Melissa acted as a tour guide stating upfront what she was about to do, while Richard's video resembled an instructional demo video made for GeoGebra users. Richard cited GeoGebra commands (walkthroughs) in his video without giving an extra explanation about why he was using that command instead of any other. The second half of his video 
Fig. 7 Olivia's use of pre-created images to facilitate the flow of her lesson

\section{Five ways for triangles to be congruent:}

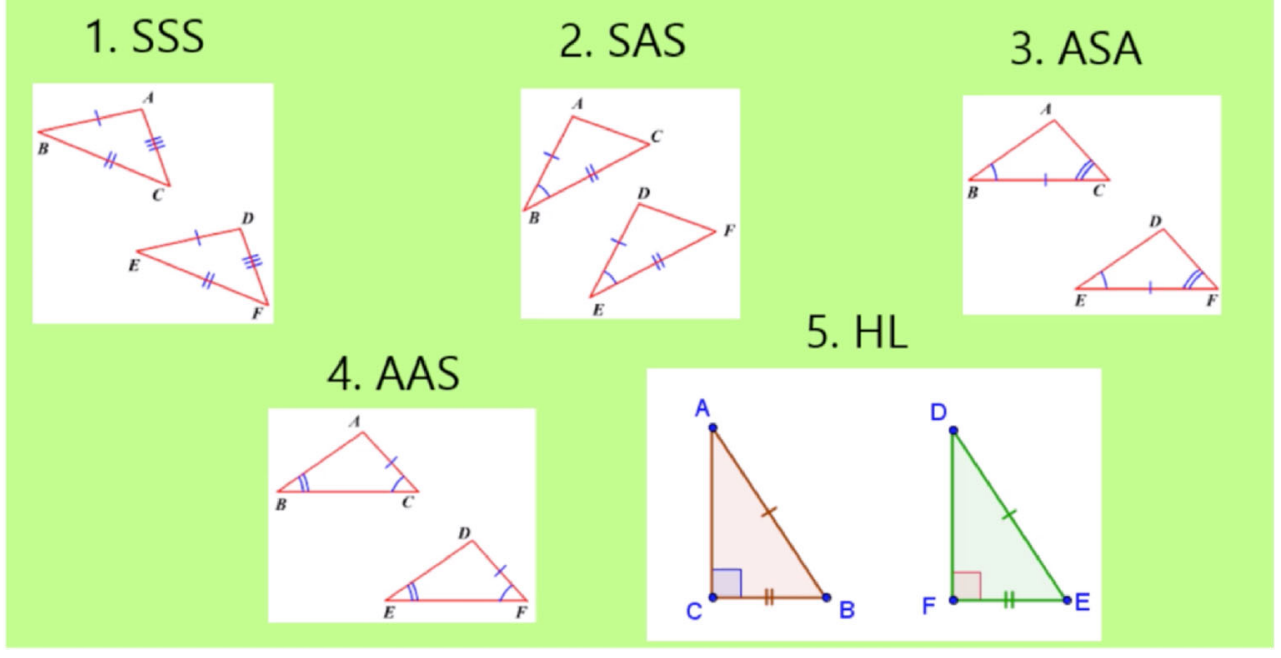

changed from GeoGebra instructional demo video to a regular video lesson in which GeoGebra was used to figure out the proof on why the four regions have equal areas.

Throughout their video lessons, participants demonstrated an integrated use of pedagogical, technological, and mathematical knowledge, which gave them a chance to experience TPACK in practice by solving a mathematical problem using conveyance and mathematical action tools in tandem. Richard emerged as an exception for TPACK balance since his video presented a high amount of technical description demonstrating his elevated technological knowledge of GeoGebra. Some participants' use of mathematical action tools had the potential of expanding the mathematical repertoire of virtual students, as we discuss in the next section.

Research Question 2: How do pre-service teachers use mathematical action technologies in their screencast video lessons?

In answering the second research question, we present how pre-service teachers used mathematical action technologies in their screencast videos. Recall that all levels of implementation of mathematical action tools happened upon the whiteboard of the screencast app (level zero), as represented in Fig. 2.

All participants, except Olivia, started their screencast video at level zero using Explain Everything to introduce the task to virtual students (see Fig. 8). Melissa and Jane kept their use of mathematical tools at level zero for more than $70 \%$ of their video lesson duration, while Richard was the only one to present the highest amount of video time (46\%) at level three, as shown in Fig. 9.

We categorized the use of mathematical action tools as level one when pre-service teachers use the tool in the form of screenshots to enhance or augment the lesson. Except Melissa, all participants implemented the mathematical action tool as level one (Fig. 8) by using GeoGebra screenshots to set-up or to complete the solution to the problem. In algebraic problems, one participant (Jane) incorporated 3D-graph images generated in GeoGebra to aid students with a visual understanding of the solution completed by her at level zero at the beginning of her video. Although participants added some form of mathematical action tool in their screencast videos at level one, their use of the math tool was in service of expediting the video streaming by presenting accurate representations, therefore, not presenting opportunities for students' reorganization of thinking.

Only one participant demonstrated the incorporation of mathematical action tool at level two in the screencast video. At this level, participants are expected to go beyond level one by adding some form of manual enhancement in the mathematical representation constructed with the mathematical tool. At level two, Jane augmented some features of the static 3Dgraphs previously created in GeoGebra. For that, she used the highlight marker from the screencast tool to emulate a hypothetical dragging movement of the cross-section representing the parabola $z=16+y^{2}$ moving along the $x$-axis, as shown in Fig. 10.

It is important to note that the augmentation represented by the translation of the parabola along the $x$-axis shown by Jane in her video is not a native feature encountered in GeoGebra. Instead, it was Jane's projected movement of parabola being translated along the $x$-axis. Her augmentation of the representation gave students a sense of movement that is not trivial in the general high school curriculum. By connecting an algebraic problem to its 3D graphical solution, Jane had the opportunity to unify these two strands of knowledge, as she shed 


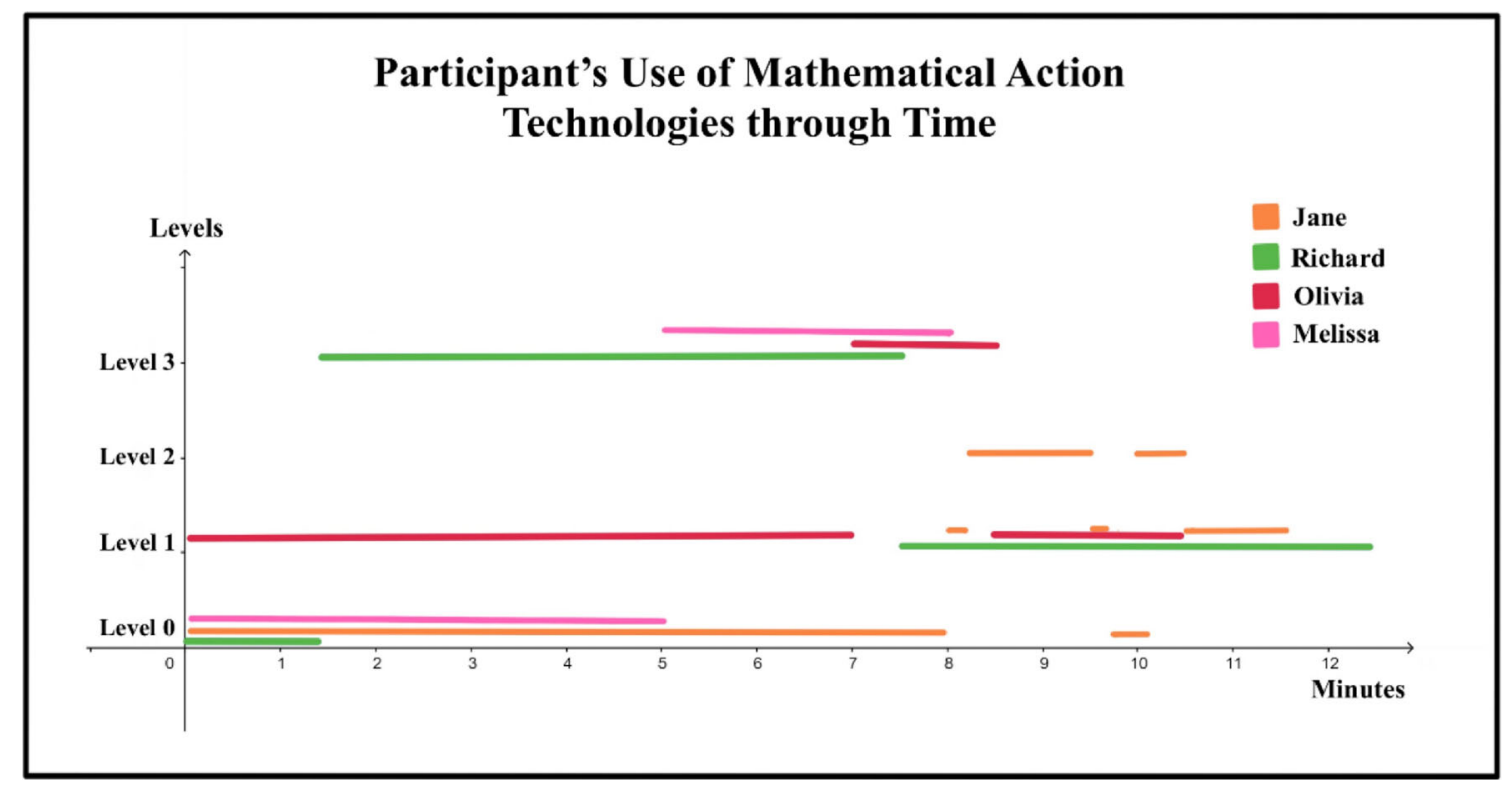

Fig. 8 Participants' use of mathematical action technologies in their screencast videos through time

light on the lively nature of this mathematical representation, in which multiple parabolas together build the surface presented in Fig. 10.

At level three, participants were expected to use a mathematical action tool in its native form, including real-time manipulation or stop-motion video bringing static mathematical objects to life. Pre-service teachers at this level implemented the mathematical action tool with a variety of pedagogical purposes. Melissa used GeoGebra and Desmos to initially confirm the solution she had previously found by hand using conveyance technology. She constructed in GeoGebra a dynamic visualization of the circle with $r^{2}=x^{2}+y^{2}$ as it hits the line $2 x+y=1$ at different points. To demonstrate this fact, Melissa varied the radius in real-time, as exemplified in Fig. 11. Similarly to Jane, Melissa's approach to the solution of the problem integrated an algebraic problem and its dynamical graphical representation, which invited students to unify these two strands of mathematical knowledge in their minds, which could lead to a potential reorganization of their mathematical understanding. Again, this knowledge integration is not trivial to high school students.

Although Richard and Olivia solved the same problem, they used the mathematical action tool at level three for different purposes. Richard used level three to set the stage for the proof, pointing out what stays invariant while showing the
Fig. 9 Relative percentages of participants' use of mathematical action technologies in their screencast videos

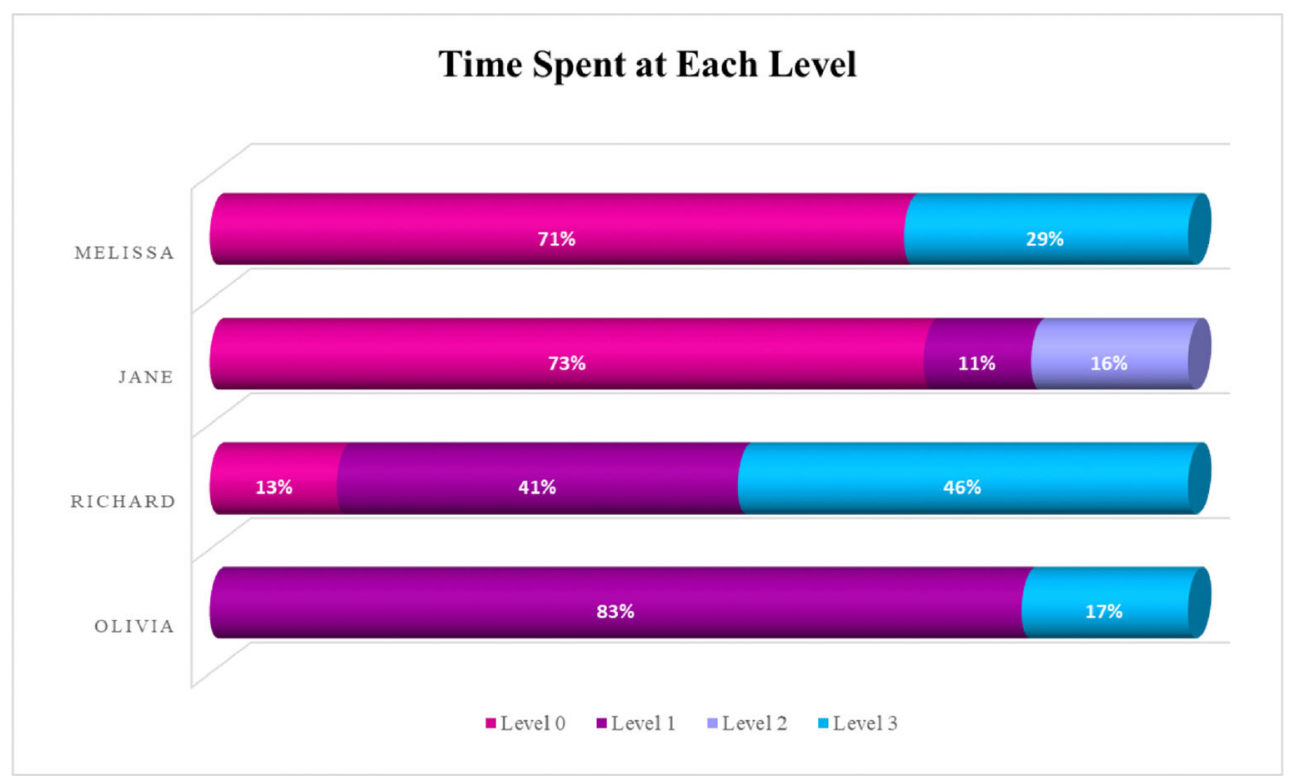




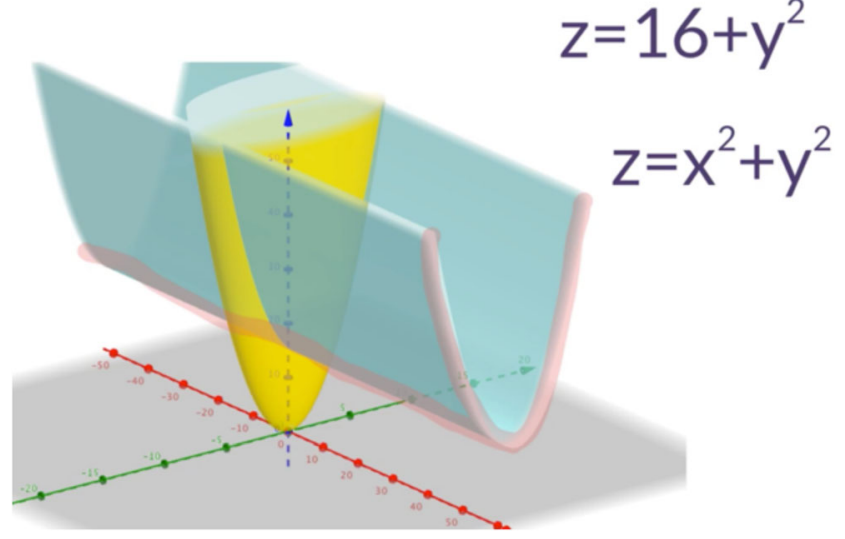

Fig. 10 Jane's augmenting a cross-section of $z=16+y^{2}$ to emulate a translation movement
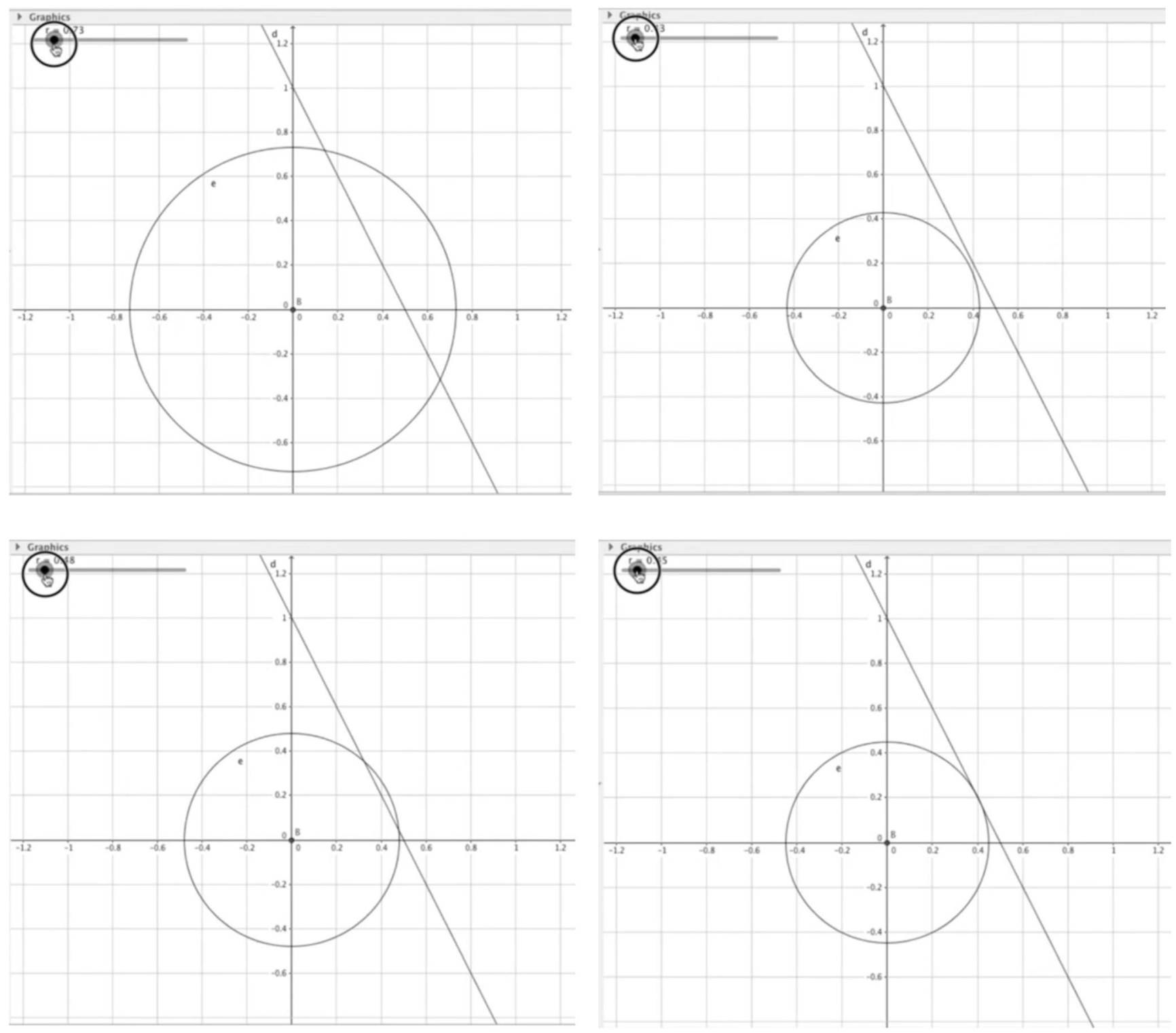

Fig. 11 Melissa expanding and contracting the circle radius to find the minimum radius as the circle intersects the line 

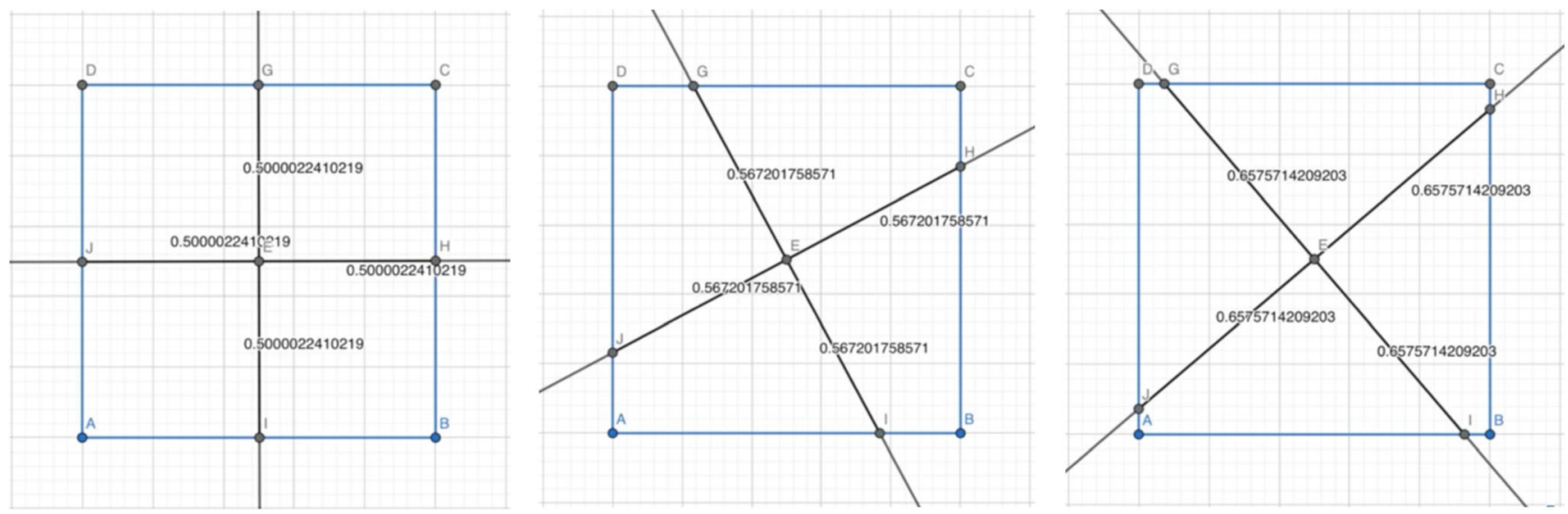

Fig. 12 Richard showing segments EG, EH, EI, and EJ have the identical length while perpendicular lines are rotated

allowed students to verify the sameness of the four areas regardless of the inclination of the perpendicular lines at different angles. Her use of mathematical action tool at level three provides opportunities for students to expand their mathematical knowledge, going from a particular case to a general solution. Similar to Richard, Olivia also used level one to wrapup the problem recapping essential elements of the solution.

\section{Discussion and Conclusions}

The project of creating screencast video lessons provided opportunities for participants to exercise the balance among their pedagogical, mathematical, and technological knowledge. In their screencast videos, participants showed effective use of technology (e.g., Explain Everything as conveyance technology, and GeoGebra as mathematical action technology), pedagogical techniques (e.g., voice pacing and questioning), and mathematical representations using technology (e.g., static and dynamic graphical representations). Literature (Kazu and Erten 2014; Koehler et al. 2011; Koh and Divaharan 2011; Harvey and Caro 2017) has reinforced the importance of teachers developing knowledge of all TPACK components. Pre-service teachers in this study presented an appropriate knowledge of the subject matter (CK), the teaching strategies (PK), and the technology chosen to be used in their video lessons (TK). However, their TPACK was not salient throughout their whole videos.

Even though some pre-service teachers (Melissa and Olivia) had shown knowledge of how to demonstrate concepts with technology (TCK), how to use pedagogical approaches in solving mathematical problems (PCK), and how to use conveyance and mathematics technologies in their teaching (TPK), their TPACK was not clearly seen from the beginning to the end of their video lessons. Our empirical results showed that during a video lesson, there were moments in which pre- service teachers' TPACK were more apparent such as when they integrated algebraic and graphical solutions into their explanation of the problem. On the other hand, TPACK was a bit hindered when mathematics technology was in service of confirming and expanding the results found by them using conveyance technology.

In our view, to have a lesson in which one can see glimpses of TPACK is not a bad feature. Our data resembles the dynamic of real classes, in which it might be challenging to observe a teacher exercising his/her TPACK throughout the whole lesson. Sometimes a teacher would have to reinforce some concepts that were previously defined by the curriculum guidelines, which would require students to learn the content without any assistance of mathematics technology. In other lessons, a teacher might be conjecturing with her/his students about some mathematical object; thus, the mathematics that emerges from this conjecturing might not be fully accurate, which would affect the balance of teacher's TPACK components. Other times, a teacher would allow students more time to interact with the mathematical tool, and it might be possible that the lesson would resemble the first half of Richard's lesson in which the commands and their functions have to be described step-by-step throughout the teaching, making it a more technical lesson, and consequently, affecting the teacher's TPACK balance.

Although all participants solved the mathematical problems correctly in their videos, there existed minor moments of lack of attention to mathematical rigor and precision. Half of the participants from this study decided to draw mathematical representations by hand (level zero). Jane drew by hand the representations of a parabola and a paraboloid, and Richard drew by hand the representations of a square. On the one hand, drawing mathematical representations by hand may have the potential of connecting that mathematical representation with hypothetical drawings virtual students would 
make if they would do it by hand without any instrument such as a ruler, compass, etc. On the other hand, by introducing inaccurate representations in their video lesson, pre-service teachers may also have induced virtual students to imprecisions or to mathematical mistakes, such as making students think that a rectangle with different sides could represent a square. Virtual students would benefit if pre-service teachers had made use of accurate pre-loaded images from the beginning of their video, as did Olivia, avoiding potential inaccuracies as they create mathematical representations by hand on the spot.

As pre-service teachers used screencast video lessons, it was possible to note the screencast app (i.e., Explain Everything) acting as an amplifier tool, expediting the writing process, the display, and accuracy of images in the video. Preservice teachers in this study did not report any difficulties when dealing with the Explain Everything standalone as they record their video lessons. On the other hand, in their reflections about this project, pre-service teachers exposed their difficulties in creating video lessons using real-time manipulation of the mathematical tool of their choice. These limitations were related to glitches presented in the Explain Everything app, which forced some students to record their video multiple times (as reported by Melissa, Olivia, and Richard in their reflection). Due to these technical difficulties between the Explain Everything app and the mathematical tool (GeoGebra) working in tandem, some participants had to change their original plan of real-time GeoGebra manipulation to implement screenshots of GeoGebra instead. All participants reported that due to these technology glitches, the video recording took much more time than they expected.

The mathematical tools implemented by pre-service teachers in their screencast videos can be used as amplifier and as reorganizer in different moments of the same screencast video. When a mathematical tool was used as amplifier it had the power to augment the lesson with more accurate mathematical representations that otherwise would be difficult and time-consuming to create by hand. In this sense, the mathematical tool was used to enhance, expedite, and streamline the existing capacity of pre-service teachers in solving the mathematical problem.

When a mathematical tool was used as reorganizer it had the power to transform the way mathematics was presented to virtual students, which could set a stage for pre-service teachers' reorganization of their mathematical knowledge for teaching. Likewise, when a pre-service teacher uses a mathematical tool as reorganizer, their lessons have the chance to transform the way mathematical concepts are presented and structured to virtual students, which, once again, has an opportunity to transform the way these students would understand mathematics. In this sense, we noticed that the mathematics technology tools were not used by pre-service teachers as a magnifier as suggested in Toyama (2011). Instead, the mathematics technology was implemented as a tool that alters how knowledge was constructed in a sense presented by Noss and Hoyles (1996). This change could happen to pre-service teachers as they exercise their TPACK by delivering a screencast video, and on the virtual students who could be watching the video and perceiving mathematics connections that were not apparent before. Thus, the results of this study align with Borba and Villarreal (2005), in which the mathematics tool influences what one knows and how one knows.

The process of teaching mathematics with technology can lead to pre-service teachers' balance of TPACK, as presented in this study. The experiences gained by pre-service teachers while they are still students may influence their future decisions about incorporating technology when teaching to their classes. Providing pre-service teachers the experience of creating screencast videos mimics their future practice in which they may have to decide which kind of technology will be the most effective for teaching certain mathematical content. For teacher educators, this study recommends the implementation of screencast video lessons in cycles of learning, in which preservice teachers will have opportunities to improve and refine their mathematical, pedagogical, and technological knowledge as they teach with conveyance and mathematics technology. We also suggest that teacher educators provide more sessions about how to use a mathematical tool of choice as a way to strengthen pre-service teachers' technological knowledge. Teacher educators should be aware that pre-service teachers might not identify the content right away that would lead to students' reorganization of their mathematical thinking. Thus, the role of a teacher educator will be essential in fostering the path of potential connections inside the mathematical content throughout the use of technology.

Most of the mathematical technologies used by teacher educators during pre-service teachers' preparation are also available to be implemented inside a tablet (e.g., Geogebra, Desmos, Fathom, Virtual Algebra Tiles, and TI Calculators). We believe it is possible to afford pre-service teachers' opportunities to create screencast video lessons while using math tools different from GeoGebra. When implementing screencast video lessons with pre-service teachers, teacher educators may consider incorporating self-regulated learning tools that could make the video more interactive for virtual students. These tools also would allow virtual students the choice of self-directing in their learning (Ponce and Mayer 2014). Delen et al. (2014) suggest note-taking, access to supplemental resources, and students' self-evaluation as three options for implementing self-regulated learning tools in video lessons. Each of these three options would work well with the type of screencast video lessons presented here.

The mathematical tasks offered to pre-service teachers in this study were everyday mathematical tasks that they would find in most high school mathematical textbooks. Although we know that there were multiple ways of solving these mathematical 
problems, these tasks did not require the implementation of a mathematical action tool by default for it to be solved. If a teacher educator would like to foster even more pre-service teachers' use of mathematical action tools in their video lessons as reorganizer, we recommend choosing high-level tasks in which the use of technology is related to the cognitive demand of the task, as suggested by Sherman (2014). On the other hand, when pre-service teachers teach lower cognitive demand tasks, teacher educators will often see them implementing mathematical action tools as amplifiers defaulting to the procedures they would take when solving the problem with paper and pencil. Thus, we recommend teacher educators coach pre-service teachers when choosing the mathematical action tool to be used in their teaching. Recalling the mathematical goals of the task may help them with the inclusion or exclusion of technology (Sherman et al. 2017).

Finally, our results showed that the simple introduction of mathematical action tools into a video lesson would not guarantee opportunities for students to integrate their mathematical thinking. Also, even if a pre-service teacher presents strong content, pedagogical, and technological knowledge, it is not possible to guarantee that his/her teaching will lead to students' reorganized learning. For that, teacher educators would have to develop activities that foster the pre-service teachers' technological dispositions and attitudes towards teaching mathematics in an integrated way. Pre-service teachers' creation of screencast video lessons can be a venue in which pre-service teachers have opportunities to transform a task into moments in which future virtual students can experience mathematical topics in an integrated way. At the same time, transforming these tasks will give teachers opportunities to experience the integration of their pedagogical, content, and technological knowledge.

In terms of research, this study contributes to the new strand in the literature related to teachers implementing tablets with Show and Tell apps. This study also extends the literature of teachers implementing tablets with Show and Tell apps by presenting how pre-service teachers made use of their Technological Pedagogical and Content Knowledge throughout their video lesson. By characterizing teachers 'use of mathematical action tools in levels, this study advances the field of research about teachers' teaching with technology, as it provides a new way of analyzing the implementation of mathematical tools by teachers.

\section{Limitations and Future Work}

The data analysis presented in this study used the TPACK framework and reorganizer/amplifier lens to understand how pre-service teachers employed their mathematical, pedagogical, and technological knowledge in their video lessons. This study could be further extended in the following ways. First, considering that pre-service teachers'
TPACK was still being developed by the time they participated in this study, it would be natural to ask if inservice teachers with more experience in both teaching mathematics and use of technology are prone to use a mathematical action tool as a reorganizer. Comparing the two groups (e.g., novice and expert teachers) in their use of screencast video lessons could shed light on what factors into the way they utilize technology and specific aspects of TPACK. Second, it is possible that teachers' views of or dispositions toward technology could affect which domains of TPACK are most actively used or which of the reorganizer and amplifier is more visible in their lesson. We plan to include pre- and post-project surveys in the follow-up study to observe the relationship between participants' views of technology and their use of TPACK. Then, investigate if there will be any changes in participants' views about technology after completing the project. Lastly, knowing that teacher's implementation technology has a potential impact on students' achievement, in future work, it would be interesting to study the relationship between the types of technology used in mathematical video lessons (reorganizer/amplifier) and the depth of pupils' understanding of the tasks covered in the videos.

Supplementary Information The online version contains supplementary material available at https://doi.org/10.1007/s11528-020-00578-1.

\section{References}

American Association of Colleges for Teacher Education (AACTE) Committee on Innovation and Technology. (2008). Handbook of technological pedagogical content knowledge (TPCK) for educators. New York: Routledge.

AMTE Committee on Innovation and Technology (2009). Mathematics TPACK (Technological Pedagogical Content Knowledge) Framework. Available at http://www.amte.net/sites/all/themes/ amte/resources/MathTPACKFramework.pdf

Borba, M. d. C., \& Villarreal, M. E. (2005). Humans-with-media and the reorganization of mathematical thinking. New York: Springer. https://doi.org/10.1007/b105001.

Cambridge Assessment International Education. (2018). Global Education Census Report. Cambridge, England: Authors. Retrieved from https://www.cambridgeinternational.org/Images/ 514611-glo bal-education-census-survey-report.pdf.

Ciampa, K. (2014). Learning in a mobile age: An investigation of student motivation. Journal of Computer Assisted Learning, 30(1), 82-96.

Cochrane, T., Narayan, V., \& Oldfield, J. (2013). iPadagogy: Appropriating the iPad within pedagogical contexts. International Journal of Mobile Learning and Organisation (IJMLO), 7(1), 4865. https://doi.org/10.1504/IJMLO.2013.051573.

Cresswell, J. W., \& Plano Clark, V. L. (2011). Designing and conducting mixed method research (2nd ed.). Thousand Oaks, CA: Sage Publications.

DeCoito, I., \& Richardson, T. (2018). Teachers and technology: Present practice and future directions. Contemporary Issues in Technology and Teacher Education, 18(2), 362-378. 
DeCuir-Gunby, J. T., Marshall, P. L., \& McCulloch, A. W. (2011). Developing and using a codebook for the analysis of interview data: An example from a professional development research project. Field Methods, 23(2), 136-155. https://doi.org/10.1177/1525822X10388468.

Delen, E., Liew, J., \& Willson, V. (2014). Effects of interactivity and instructional scaffolding on learning: Self-regulation in online video-based environments. Computers \& Education, 78, 312-320.

Dick, T., \& Hollebrands, K. (2011). Focus on reasoning and sense making: Technology. Reston, VA: National Council of Teachers of Mathematics.

Gecu-Parmaksiz, Z., \& Delialioglu, O. (2019). Augmented realitybased virtual manipulatives versus physical manipulatives for teaching geometric shapes to preschool children. British Journal of Educational Technology, 50(6), 3376-3390. https://doi.org/10. 1111/bjet.12740.

Geer, R., White, B., Zeegers, Y., Au, W., \& Barnes, A. (2017). Emerging pedagogies for the use of iPads in schools. British Journal of Educational Technology, 48(2), 490-498. https://doi.org/10.1111/ bjet.12381.

Golafshani, N. (2003). Understanding reliability and validity in qualitative research. Qualitative Report, 8(4), 597.

Goodwin, K. (2012). Use of tablet technology in the classroom. State of New South Wales: NSW Department of Education and Communities.

Harvey, D. M., \& Caro, R. (2017). Building TPACK in Preservice teachers through explicit course design. TechTrends, 61, 106-114. https://doi.org/10.1007/s11528-016-0120-x.

Haßler, B., Major, L., \& Hennessy, S. (2016). Tablet use in schools: A critical review of the evidence for learning outcomes: Tablet use in schools: A critical review. Journal of Computer Assisted Learning, 32(2), 139-156. https://doi.org/10.1111/jcal.12123.

Heinrich, P. (2012). The iPad as a tool for education: A study of the introduction of iPads at Longfield Academy, Kent. In Nottingham, UK: NAACE. The ICT Association Retrieved from: http://www. elearningfoundation.com/Websites/elearningfoundation/images/ PDF_Documents/Longfield-The_iPad_as_a Tool_for_Education. pdf.

Ingram, N., Williamson-Leadley, S., Bedford, H., \& Parker, K. (2015). Using show and tell tablet technology in mathematics. In R. Averill (Ed.), Mathematics and statistics in the middle years: Evidence and practice (pp. 18-34). Wellington: NZCER.

Ingram, N., Williamson-Leadley, S., \& Pratt, K. (2016). Showing and telling: Using tablet technology to engage students in mathematics. Mathematics Education Research Journal, 28(1), 123-147.

Ingram, N., Pratt, K., \& Williamson-Leadley, S. (2018). Using show and tell apps to engage students in problem-solving in the mathematics classroom. In N. Calder, K. Larkin, \& N. Sinclair (Eds.), Using Mobile Technologies in the Teaching and Learning of Mathematics. Mathematics Education in the Digital Era, vol 12. Cham: Springer.

Jahnke, I., \& Kumar, S. (2014). Digital didactical designs: Teachers' integration of iPads for learning-centered processes. Journal of Digital Learning in Teacher Education, 30(3), 81-88. https://doi. org/10.1080/21532974.2014.891876.

Kazu, I., \& Erten, P. (2014). Teachers' technological pedagogical content knowledge self-efficacies. Journal of Education and Training Studies, 2(2), 126-144. https://doi.org/10.11114/jets.v2i2.261.

Koehler, M. J., \& Mishra, P. (2005). What happens when teachers design educational technology? The development of technological pedagogical content knowledge. Journal of Educational Computing Research, 32(2), 131-152. https://doi.org/10.2190/0EW7-01WBBKHL-QDYV.

Koehler, M. J., Mishra, P., Bouck, E. C., DeSchryver, M., Kereluik, K., Shin, T. S., \& Wolf, L. G. (2011). Deep-play: Developing TPACK for 21 st century teachers. International Journal of Learning Technology, 6(2), 146-163.
Koehler, M., Greenhalgh, S., Rosenberg, J., \& Keenan, S. (2017). What the tech is going on with teachers' digital teaching portfolios? Using the TPACK framework to analyze teachers' technological understanding. Journal of Technology and Teacher Education, 25(1), $31-59$.

Koh, J. H. L., \& Divaharan, S. (2011). Developing pre-service teachers' technology integration expertise through the TPACK-developing instructional model. Journal of Educational Computing Research, 44(1), 35-58. https://doi.org/10.2190/EC.44.1.c.

Korenova, L. (2017). GeoGebra in teaching of primary school mathematics. The international Journal for Technology in Mathematics Education, 24(3), 155-160. https://doi.org/10.1564/tme_v24.3.08.

Landry, G, A. (2010). Creating and Validating an Instrument to Measure Middle School Mathematics Teachers'Technological Pedagogical Content Knowledge (TPACK). [Doctoral Dissertation, The University of Tennessee]. Retrieved from: https://trace.tennessee. $\mathrm{edu} / \mathrm{cgi} /$ viewcontent.cgi?article $=1727 \&$ context $=$ utk_graddiss .

Lapan, S. D., Quartaroli, M. T., \& Riemer, F. J. (2012). Qualitative research: An introduction to methods and designs. San Francisco: Jossey-Bass.

Lee, H., \& Hollebrands, K. (2008). Preparing to teach mathematics with technology: An integrated approach to developing technological pedagogical content knowledge. Contemporary Issues in Technology and Teacher Education, 8(4), 326-341.

Mishra, P., \& Koehler, M. J. (2006). Technological pedagogical content knowledge: A new framework for teacher knowledge. Teachers College Record, 108(6), 1017-1054.

Moon, M. D. (2019). Triangulation: A method to increase validity, reliability, and legitimation in clinical research. Journal of Emergency Nursing, 45(1), 103-105. https://doi.org/10.1016/j.jen.2018.11.004.

Mouza, C., \& Barrett-Greenly, T. (2015). Bridging the app gap: An examination of a professional development initiative on mobile learning in urban schools. Computers and Education, 88, 1-14. https:// doi.org/10.1016/j.compedu.2015.04.009.

National Council of Teachers of Mathematics. (2000). Principles and standards for school mathematics. Reston, VA: National Council of Teachers of Mathematics.

Niess, M. L., Ronau, R. N., Shafer, K. G., Driskell, S. O., Harper, S. R., Johnston, C., Browning, C., Özgün-Koca, S. A., \& Kersaint, G. (2009). Mathematics teacher TPACK standards and development model. Contemporary Issues in Technology and Teacher Education, 9(1), 4-24.

Noss, R., \& Hoyles, C. (1996). Windows on mathematical meanings: Learning cultures and computers. Dordrecht: Kluwer Academic Publishers.

Outhwaite, L. A., Gulliford, A., \& Pitchford, N. J. (2017). Closing the gap: Efficacy of a tablet intervention to support the development of early mathematical skills in UK primary school children. Computers \& Education, 108, 43-58. https://doi.org/10.1016/j.compedu.2017. 01.011 .

Patton, M. Q. (2002). Qualitative Research \& Evaluation Methods (3rd ed.). Thousand Oaks, CA: Sage Publications.

Pea, R. D. (1985). Beyond amplification: Using the computer to reorganize mental functioning. Educational Psychologist, 20, 167-182.

Pea, R. D. (1987). Integrating human and computer intelligence. In R. D. Pea \& K. Sheingold (Eds.), Mirrors of mind: Patterns of experience in educational computing (pp. 128-146). Norwood, NJ: Ablex.

Pitchford, N. J. (2015). Development of early mathematical skills with a tablet intervention: A randomized control trial in Malawi. Frontiers in Psychology, 6, 485. https://doi.org/10.3389/fpsyg.2015.00485.

Ponce, H. R., \& Mayer, R. E. (2014). Qualitatively different cognitive processing during online reading primed by different study activities. Computers in Human Behavior, 30, 121-130. https://doi.org/ 10.1016/j.chb.2013.07.054. 
Quillen, I. (2011). Tablet culture. Education Week, pp. 38, 40-41. Retrieved from http://www.edweek.org/dd/articles/2011/06/15/ 03mobile.h04.html

Schacter, J., \& Jo, B. (2017). Improving preschoolers' mathematics achievement with tablets: A randomized controlled trial. Mathematics Education Research Journal, 29(3), 313-327. https:// doi.org/10.1007/s13394-017-0203-9.

Schmidt, D. A., Baran, E., Thompson, A. D., Mishra, P., Koehler, M. J., \& Shin, T. S. (2009). Technological pedagogical content knowledge (TPACK): The development and validation of an assessment instrument for preservice teachers. Journal of Research on Technology in Education, 42(2), 123-149. https://doi.org/10.1080/15391523. 2009.10782544.

Sherman, M. (2014). The role of technology in supporting students' mathematical thinking: Extending the metaphors of amplifier and reorganizer. Contemporary Issues in Technology and Teacher Education, 14(3), 220-246.

Sherman, M. F., Cayton, C., \& Chandler, K. (2017). Supporting PSTs in using appropriate tools strategically: A learning sequence for developing technology tasks that support students' mathematical thinking. Mathematics Teacher Educator, 5(2), 122-157. https://doi.org/ 10.5951/mathteaceduc.5.2.0122.

Shulman, L. S. (1986). Those who understand: Knowledge growth in teaching. Educational Researcher, 15(2), 4-14.

Shulman, L. S. (1987). Knowledge and teaching: Foundations of the new reform. Harvard Educational Review, 57(1), 1-22.
Toyama, K. (2011). Technology as an amplifier in international development. In Proceedings of the 2011 iConference, 75-82. DOI:https:// doi.org/10.1145/1940761.1940772.

van der Ven, F., Segers, E., Takashima, A., \& Verhoeven, L. (2017). Effects of a tablet game intervention on simple addition and subtraction fluency in first graders. Computers in Human Behavior, 72, 200-207. https://doi.org/10.1016/j.chb.2017.02.031.

Walsh, V., \& Farren, M. (2018). Teacher attitudes regarding barriers to meaningfully implementing iPads in a primary school setting. Computers in the Schools, 35(2), 152-170. https://doi.org/10. 1080/07380569.2018.1462674.

Williamson-Leadley, S., \& Ingram, N. (2013). Show and tell: Using iPads for assessment in mathematics. Computers in New Zealand Schools: Learning, Teaching, Technology, 25(1-3), 117-137.

Zhang, Y., \& Wildemuth, B. M. (2009). Qualitative analysis of content. In B. M. Wildemuth (Ed.), Applications of social research methods to questions in information and library science, libraries unlimited (pp. 308-319). CT: Westport.

Zhang, M., Trussell, R. P., Gallegos, B., \& Asam, R. R. (2015). Using math apps for improving student learning: An exploratory study in an inclusive fourth grade classroom. TechTrends, 59(2), 32-39. https://doi.org/10.1007/s11528-015-0837-y.

Publisher's Note Springer Nature remains neutral with regard to jurisdictional claims in published maps and institutional affiliations. 